\title{
THERMAL ANALYSIS OF A REFINED APT POWER COUPLER AND THERMAL SHIELD AND THE EFFECT ON THE CRYOPLANT*
}

\author{
R. Bourque ${ }^{* *}$ and G. Laughon", General Atomics, San Diego, CA 92186, USA
}

\begin{abstract}
The present APT cryomodule shield cooling circuit employs helium gas up to 18 bars in order to operate at $4.6 \mathrm{~K}$ inlet temperatures without flow instabilities. The high pressure adds complexity to the cryoplant and cryogen distribution system. The low supply temperature, needed because a series flow circuit is used, increases the cryoplant refrigeration power. This paper describes a lower pressure cooling circuit operating at a high enough supply temperature that flow instabilities do not occur. The shield flow circuit is changed from series to parallel; and modifications are made to the designs of the power coupler outer conductor, thermal intercepts, thermal shield, and end beam tubes. This redesign results in a small decrease in cryoplant compressor power.
\end{abstract}

\section{INTRODUCTION}

This paper presents a cryogenic cooling approach for the APT superconducting cryomodules. During the Engineering Design and Demonstration (ED\&D) part of the APT project, a design [1] emerged which:

1. Maintains all of the niobium material, including power coupler attachment ports, below the critical temperature of niobium, $\mathrm{T}_{\mathrm{c}}$, of $9.26 \mathrm{~K}$,

2. Minimizes heat load to the $2.15 \mathrm{~K}$ liquid helium, and

3. Minimizes the heat load to the shield coolant

These objectives were not easy to achieve in a $\mathrm{CW}$ accelerator where the $700 \mathrm{MHz}$ RF power into the power coupler reaches $210 \mathrm{~kW}$ [2]. The solution adopted for the shield circuit was to employ helium gas coolant which enters the cryomodule at $4.6 \mathrm{~K}$ and up to 18 bars pressure, and exits at $28 \mathrm{~K}$ after passing in series through all the power couplers in the cryomodule. The high pressure was needed to minimize density fluctuations [3], which cause flow instabilities in this low temperature range.

\section{OBJECTIVES}

While the ED\&D design solution satisfies the cryogenic cooling objectives above, there are a number of concerns:

1. The high pressure helium increases the complexity of the cryoplant.

2. The low supply temperature increases the cryoplant compressor power for a given heat load.

3. Most other facilities use higher temperatures and lower pressures, and therefore there is more operating experience with this parameter range. The main objective of this study was to see if a more conventional cooling approach with lower pressure and higher temperature

\footnotetext{
* Supported by US DOE Contact DE-AC04-96-89607.

** robert.bourque@gat.com,_ \# laughon@jlab.org
}

could be adopted. At or above 16-20 K, helium behaves nearly like an ideal gas at all pressures of interest.

\section{HEAT LOADS}

In the new design, the cryomodule components are cooled by three streams: (1) 4.0 bar helium gas entering at $20 \mathrm{~K}$ and exiting at $30 \mathrm{~K}$ (called the shield circuit), (2) $2.15 \mathrm{~K}$ saturated liquid helium (called the $2 \mathrm{~K}$ circuit), and (3) room-temperature water or helium gas. The reason for having the first is to minimize heat loads to the second. The last is to cool the warm end of the power coupler outer conductor and all the inner conductor.

The challenge was even greater here because a design change reduced the number of power couplers per cavity from two to one. The RF power to each coupler was increased from $210 \mathrm{~kW}$ to $420 \mathrm{~kW}$.

The heat loads to the shield circuit are:

1. Most of the resistive dissipation of the RF power in the power coupler outer conductor (some goes to $2 \mathrm{~K}$ ).

2. Thermal radiation to the thermal shield from the room-temperature inner wall of the vacuum tank. This is greatly reduced by wrapping the thermal shield in multilayer insulation (MLI). A value of $1.3 \mathrm{~W} / \mathrm{m}^{2}$, taken from [1], is used.

3. Thermal conduction along parts that connect the room temperature components to the cryogenic components. These include the power coupler outer conductors, end beam tubes, tuner levers, component supports, cryogenic bayonet connectors, relief valves, and J-T valves.

The heat loads to the $2 \mathrm{~K}$ circuit are:

1. RF resistive loads in the cavity. These are the dominant $2 \mathrm{~K}$ heat load.

2. Some of the resistive dissipation of the RF power in the outer walls of the power coupler. Most is intercepted by the shield circuit.

3. Thermal radiation from the warm power coupler inner conductor. Because of the low emissivity of cold copper and niobium, this radiation is spread over the $2 \mathrm{~K}$ surfaces by multiple reflections.

4. Thermal radiation from the thermal shield. This shield is at $40-50 \mathrm{~K}$, so thermal radiation is very low. It is reduced to insignificant values by adding an inner layer of MLI, which also serves to mitigate thermal spikes.

5. Residual thermal conduction along tuner levers, component supports, cryogenic bayonet connectors, relief valves, and $\mathrm{J}-\mathrm{T}$ valves.

6. Power dissipated resistively in the higher-order-mode (HOM) couplers. This is taken to be $10 \%$ of the total HOM loss.

The heat loads recalculated in this study due to the design changes are: 
1. Power coupler inner conductor heat loads to $2 \mathrm{~K}$.

2. Power coupler outer conductor heat loads to shield circuit and $2 \mathrm{~K}$ circuit. The surface resistance of the copper plating was modeled as a RRR25 copper based on experimental data [4]. Resistive dissipation at room temperature was determined during the ED\&D program. These data were scaled to cryogenic temperature using the ratio of surface resistances.

3. End beam tube heat loads to shield circuit and $2 \mathrm{~K}$ circuit. Bellows needed to take up deflections were exploited to minimize these loads.

4. Thermal shield heat loads and conduction paths.

This paper concentrates mainly on the power coupler. Further details are given in [5].

\section{POWER COUPLER OUTER CONDUCTOR DESIGN AND MODELING}

\subsection{Design Changes}

The power coupler outer conductor was modified, as shown schematically in Fig. 1. The intercept heat exchanger on the cold end has been altered to oncethrough annular-flow. Also, heat from the thermal shield passes via a copper shunt to that heat exchanger, eliminating cooling tubes on the shield. There is a copper intercept at the stainless steel/niobium interface, needed to maintain the niobium port temperature below $\mathrm{T}_{\mathrm{c}}$. It shunts heat to the cavity helium vessel.

At the warm end, there is a $1.0 \mathrm{~mm}$ outer layer of copper on the outer conductor. This conducts heat to a room-temperature coolant (air, water, or helium).

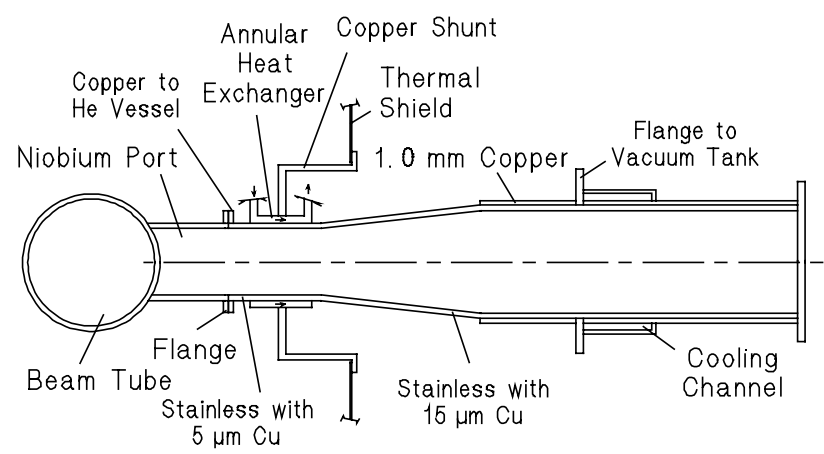

Figure 1: Modified outer conductor of the power coupler.

The taper and warm end each have a 15 micron coating of copper on the inside. The cylindrical cold end has a 5 micron coating. Both are several $700 \mathrm{MHz}$ skin depths at an apparent RRR of 25 for surface resistance. The thermal RRR is taken to be 200, which is what was found in the Cryogenic Test Rig experiment at LANL [3].

\subsection{Thermal Modeling}

The Cosmos/M finite element program was used to determine temperature distributions and heat fluxes in the power coupler, end beam tube and thermal shield. Temperature-dependent thermal conductivities and thermal expansivities were used.
Figure 2 shows the half-model used for the thermal analysis of the power coupler. It includes an arbitrary portion of the vacuum tank, which contributes some area for natural convection assuming the power coupler is rigidly attached to it. The numbered sectors in the figure have different materials, thicknesses, and heat and cooling loads. Details of these loads are given in [5]. The RF power and resulting heat fluxes are doubled from the ED\&D program to account for one coupler, rather than two, per cavity.

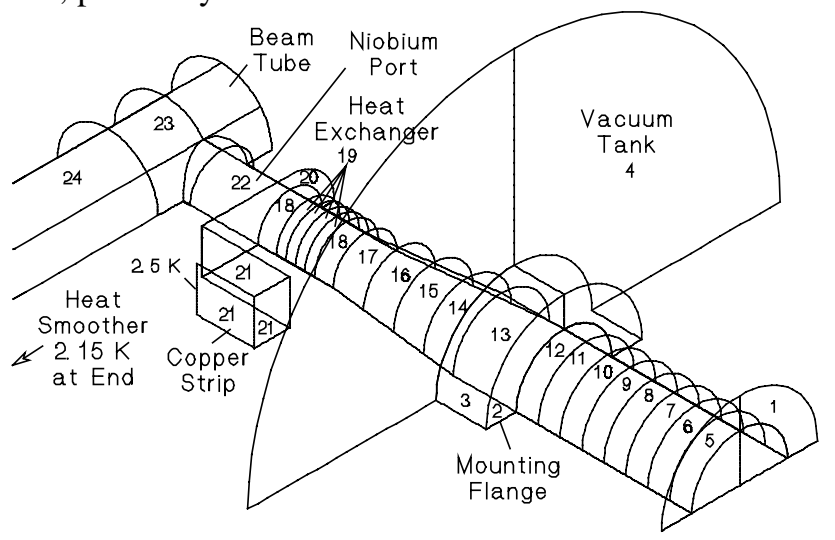

Figure 2: Model used in power coupler thermal analysis.

The heat "smoother" (sector 24 in the figure) is an artificial extreme conductivity material that shifts the heat flux to purely axial, making it easier to pick off values. It has no effect on results.

\section{RESULTS}

Figure 3 shows the full-range temperature distribution resulting from the Cosmos analysis with $420 \mathrm{~kW}$ of $\mathrm{RF}$ input power. The peak temperature of $344 \mathrm{~K}(71 \mathrm{C})$ occurs in the warm section of the taper. It can be reduced by increasing the thickness of the copper outer layer, or extending the coolant further into the power coupler.

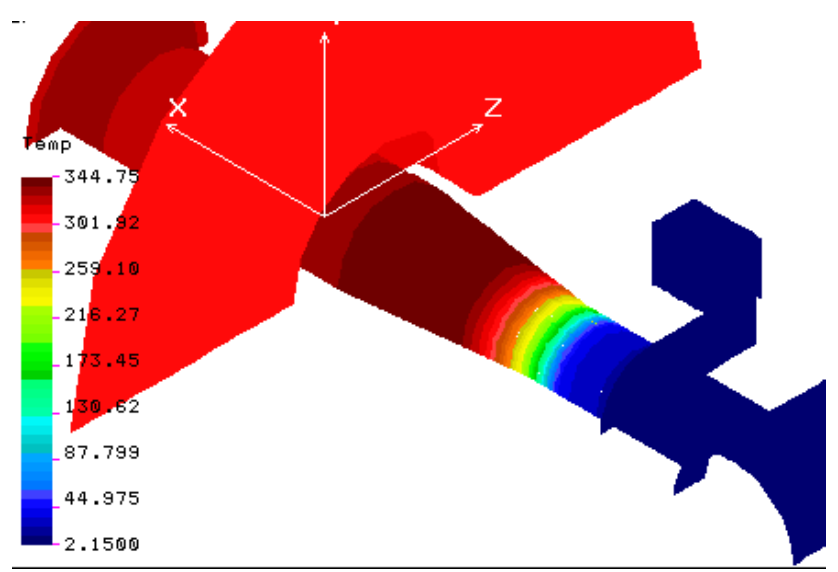

Figure 3: Temperature distribution in power coupler, niobium port and beam tube. Beam tube is at lower right.

Figure 4 shows the niobium and copper intercept temperature distributions over a range of $2.15-9 \mathrm{~K}$. The copper intercept flange (item 20 in Fig. 2) is $10 \mathrm{~mm}$ thick 
to reduce the transverse temperature gradient. The copper strip thickness is $1.8 \mathrm{~mm}$ thick, which gives a peak niobium temperature of about $1.0 \mathrm{~K}$ below the niobium $\mathrm{T}_{\mathrm{c}}$. Heat flows to $2 \mathrm{~K}$ through both the copper strip (30\% of the heat) and the niobium itself (70\%).

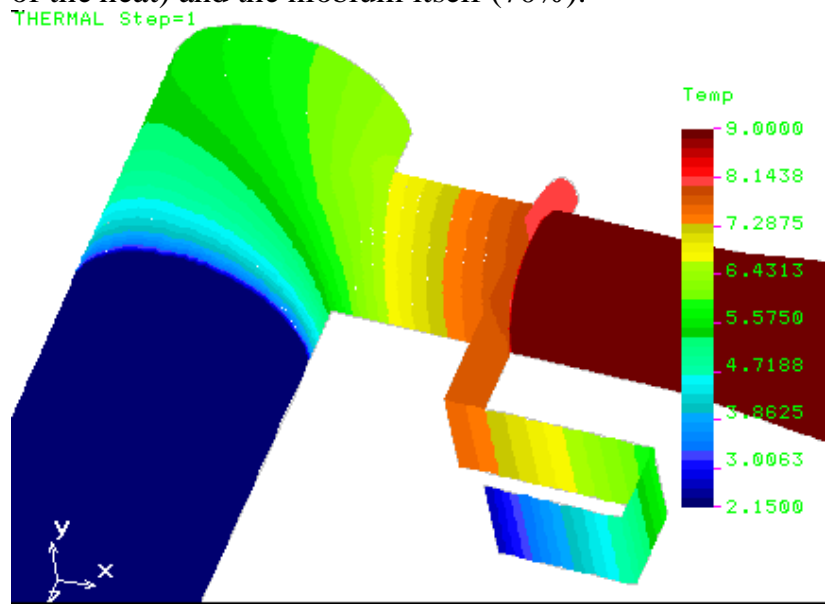

Figure 4: Niobium port, beam tube, and copper intercept temperatures

Table 1 shows the resulting heat loads to the shield and $2 \mathrm{~K}$ circuits. These heat loads are for one power coupler. The shield circuit load is about the same as reported in [2] when adjusted for one power coupler per cavity. The $2 \mathrm{~K}$ load has increased 3-4 W per cavity, about a $15 \%$ increase in the $2 \mathrm{~K}$ load from the power coupler. Table 2 shows the overall effect on the cryoplant including all heat loads. As seen, the $2 \mathrm{~K}$ circuit power increased by $3.2 \%$, while the shield power has been reduced by $61 \%$.

Table 1: Heat Loads and $\mathrm{Nb}$ Temperature for Power Coupler (420 kW RF)

\begin{tabular}{|l|c|}
\hline Peak niobium temperature & $\mathbf{8 . 1 1}$ K \\
\hline Shield (20 K) Circuit: & $32.29 \mathrm{~W}$ \\
\hline $\begin{array}{l}\text { Conduction to ends of 20 K heat } \\
\text { exchanger }\end{array}$ & $3.76 \mathrm{~W}$ \\
\hline $\begin{array}{l}\text { RF resistive heating under 20 K heat } \\
\text { exchanger }\end{array}$ & $\mathbf{3 6 . 1 4} \mathbf{~ W}$ \\
\hline Total to 20 K from power coupler & $1.88 \mathrm{~W}$ \\
\hline 2 K Circuit: & $4.55 \mathrm{~W}$ \\
\hline Conduction through copper strip & $\mathbf{6 . 4 3} \mathbf{~ W}$ \\
\hline $\begin{array}{l}\text { Conduction through niobium to heat } \\
\text { smoother }\end{array}$ & \\
\hline Total to 2 K circuit from power coupler & \\
\hline
\end{tabular}

This result is from the lower Carnot work due to the increased shield supply temperature and from improvements in the power coupler design. Even though the $2 \mathrm{~K}$ load represents the greater fraction of the required power, the shield circuit improvements result in a net reduction of $7.9 \%$ in total cryoplant electrical power.

Additional benefits from the reduction in shield coolant pressure and increased temperature are:
1. The refrigeration cycle is simplified by eliminating the requirement for a high pressure $4.5 \mathrm{~K}$ flow.

2. Operating the shield at 4 atmospheres rather than 18 will allow for simplified expansion joints like those currently in use at TJNAF, and lower transfer line anchoring loads.

3. The lower pressure also eliminates the potential need for transfer line relief valves in the linac tunnel.

Table 2: Comparison of cryoplant electrical power $(\mathrm{kW})$

\begin{tabular}{|c|c|c|c|}
\hline Circuit & ED\&D & This Design & Change \\
\hline 2 K & 6000 & 6190 & $+3.2 \%$ \\
\hline Shield & 1240 & 480 & $-61 \%$ \\
\hline Total & 7240 & 6670 & $\mathbf{- 8 \%}$ \\
\hline
\end{tabular}

\section{SUMMARY}

It is feasible and attractive to employ a cryomodule cryogenic cooling scheme that has a lower pressure and higher supply temperature in the shield cooling circuit than in the design developed in APT ED\&D program. The ED\&D shield circuit with 18 bar helium and $4.6 \mathrm{~K}$ inlet temperature is replaced with 4 bar helium and $20 \mathrm{~K}$ inlet. This moves the gas away from the region of large density fluctuations to nearly ideal gas conditions. The effect on heat loads is such that the $2 \mathrm{~K}$ circuit received slightly more heat, while the shield circuit remains about the same. Because of the greater refrigeration efficiency at the higher shield circuit temperature, the net effect on the cryoplant is a nearly eight percent reduction in electrical power needed to drive the compressors. Simplifications to the cryoplant provide an added benefit.

\section{ACKNOWLEDGEMENTS}

It is a pleasure to acknowledge useful comments and suggestions from G. Spalek and V. DelBene (GA), and J. Waynert, F. Krawczyk, E. Schmierer, D. Schrage, and D. Chan (LANL).

\section{REFERENCES}

[1] J. Waynert, "Preliminary Estimate of APT Cryomodule Heat Loads", LANL memo ESA-EPE: 99-029, Nov 1998.

[2] E. Schmierer, "Implications of Using Water to Cool the APT ED\&D Power Coupler Inner Conductor", LANL Memo ESADE-01-001, Oct 25, 2000.

[3] J.P. Kelley, "Thermally Induced Flow Oscillations in the Double Point Intercept Power Coupler Circuit", LANL memo Lansce-1:98-213, Dec 8, 1998.

[4] D. J. Liska and G. O. Bolme, "The Surface Treatment of Copper for High-Q Applications in Cryogenic RF Cavities", LANL preprint LA-CP-90-214, in 2nd N. P. Beam Technical Symposium, May 20- 24, 1980.

[5] R. Bourque and G. Laughon, "A Cryomodule Cooling Method Using Moderate-Pressure Helium in the Shield Circuit", APT Document PPO-A13-M-TRT-X-00231, Feb, 2001. 